\title{
Designation of a Neotype Strain for Moraxella bovis (Hauduroy et al.) Murray
}

\author{
S. D. HENRIKSEN \\ Kaptein W. Wilhelmsen og Frues Bakteriologiske Institutt, University of Oslo, \\ Rikshospitalet, Oslo 1, Norway
}

ATCC 10900 is designated as the neotype strain of Moraxella bovis (Hauduroy et al. 1937) Murray 1948. A description of the type strain is given.

A type strain for Moraxella bovis (Hauduroy et al. 1937) Murray 1948 has not yet been designated. It appears that none of the original strains of this organism, initially described by Jones and Little (3), exist. Several strains of $M$. bovis have been used extensively in recent research (2), including the cooperative studies just completed by members of the International Subcommittee on the Taxonomy of Moraxella and Allied Bacteria. One of these strains, ATCC 10900 , appears to be an entirely typical strain and to possess all the characters reported by Jones and Little (3) in their first description of this organism. According to the information received, this strain was isolated by Barner (1) from a case of keratoconjuctivitis in cattle. ATCC 10900 is here designated as the neotype strain for Moraxella bovis (Hauduroy et al.) Murray.

\section{Description of the neotype strain.}

Micromorphology: Short rods, ca. 1 by $2 \mu \mathrm{m}$, occurring predominantly in pairs, occasionally in short chains; no marked pleomorphism, no capsules, no spores, no swimming motility. Gram-negative with some tendency to retain the blue stain.

Colonies: Ca.1.5 mm in diameter after $20 \mathrm{hr}$; low convex or flat, round, glistening, nonmucoid, nonpigmented, semi-opaque. On blood agar colonies are surrounded by zones of beta-hemolysis 3 to $4 \mathrm{~mm}$ in diameter after 20 hr.

Growth characteristics: Strict aerobe. Grows as well at 30 to $32 \mathrm{C}$ as at $37 \mathrm{C}$. Grows on peptone water and on nutrient agar without additions, but growth is poor and irregular on some fluid media (indole, nitrate, VogesProskauer). Feeble growth on the surface of Hugh and Leifson's O-F-medium.

Biochemical reactions: Catalase, citrate, urease, nitrate, indole, $\mathrm{H}_{2} \mathrm{~S}$, and phenylalanine deaminase reactions are all negative. Oxidase reactions are positive with dimethyl- and tetramethyl- $p$-phenylenediamine. No sugars fermented. Gelatin liquefied.

Antibiotic sensitivity: Highly sensitive to penicillin, streptomycin, chloramphenicol, tetracyclines, erythromycin.

Deoxyribonucleic acid base composition: 42.5 moles per cent guanine plus cytosine.

Genetic relationships: Highly compatible in transformation with other strains of the same species. Moderately compatible with $M$. lacunata, $M$. nonliquefaciens, and $M$. liquefaciens (M. lacunata subspecies liquefaciens).

\section{LITERATURE CITED}

1. Barner, R. D. 1952. A study of Moraxella bovis and its relation to bovine keratitis. Amer. J. Vet. Res. 13:132-144.

2. Bøvre, K. 1965. Transformation in Moraxella and organisms assumed to be related to Moraxella. 3 . Quantitative streptomycin resistance transformation between Moraxella bovis and Moraxella nonliquefaciens strains. Acta Pathol. Microbiol. Scand. 63:42-50.

3. Jones, F. S., and R. B. Little. 1923. An infectious ophthalmia of cattle. J. Exp. Med. 38:139-148. 